\title{
An operation for anomalous origin of left coronary artery
}

\author{
D. I. HAMILTON, P. K. GHOSH, AND R. J. DONNELLY \\ From the Department of Cardiac Surgery, Royal Liverpool Children's Hospital, Liverpool
}

SUMMARY Successful surgical correction for anomalous origin of the left coronary artery from the pulmonary artery in a 4-year-old child is reported. An aortopulmonary fistula was created and a pericardial baffle was inserted within the pulmonary artery to connect the fistula to the ostium of the left coronary artery. The clinical, haemodynamic, and angiographic features of the anomaly are presented. The child's progress is satisfactory 17 months after the operation.

The majority of coronary artery malformations are anomalies in the site of origin-71 per cent in the necropsy series of Van Praagh (1973). In 26 per cent of cases the left coronary artery arose from the pulmonary artery. Thibert et al. (1973) pointed out that these anomalies should be defined as anomalous origin of the left coronary artery with drainage into the left posterior pulmonary sinus. Though these anomalies have been classified into 'adult' and 'infant' types (Augustsson et al., 1962), there is overlap in the clinical presentation. Mortality is high in symptomatic infants having the so-called BlandWhite-Garland syndrome (Billig, 1973). Though children above the age of 2 years have a favourable life expectation during childhood, the increasing morbidity of mitral regurgitation, progressive myocardial ischaemia, and congestive cardiac failure all militate against a normal life span and make surgical correction desirable.

A child with this anomaly has been treated surgically in this clinic by the creation of an aortopulmonary fistula and the insertion of a pericardial baffle within the pulmonary artery to connect the fistula to the ostium of the left coronary artery.

\section{Case report}

R.V., a baby girl was born by lower segment caesarean section for fetal distress at 38 weeks of gestation. The birthweight was $2 \cdot 85 \mathrm{~kg}$.

Tachypnoea was noticed at the age of 2 weeks, particularly after large feeds. The baby developed a respiratory infection at 3 months. The chest $x$-ray showed gross cardiomegaly. A clinical diagnosis of endocardial fibroelastosis was made. Cardiac cathe- terisation (Table) and left ventricular cineangiography disclosed a dilated and poorly contracting left ventricle. The right coronary artery was enlarged and tortuous. Mitral regurgitation was present. After treatment with digoxin her tachypnoea, pallor, and atrial gallop rhythm disappeared. She took feeds well and gained weight.

Table Haemodynamic data

\begin{tabular}{|c|c|c|c|c|}
\hline \multirow[t]{2}{*}{ Site } & \multicolumn{2}{|c|}{ Age 16 months } & \multicolumn{2}{|c|}{ Age 3 years 9 months } \\
\hline & $\begin{array}{l}\text { Pressure } \\
(\mathrm{mmHg})\end{array}$ & $\begin{array}{l}\text { Oxygen } \\
\text { saturation } \\
(\%)\end{array}$ & $\begin{array}{l}\text { Pressure } \\
(\mathrm{mm} H g)\end{array}$ & $\begin{array}{l}\text { Oxygen } \\
\text { saturation } \\
(\%)\end{array}$ \\
\hline Right atrium & & 65 & $\begin{array}{l}\text { a } 5, \text { v } 5 \\
\text { m } 4\end{array}$ & 67 \\
\hline $\begin{array}{l}\text { Right ventricle } \\
\text { Pulmonary artery } \\
\text { Left atrium }\end{array}$ & $\begin{array}{l}35 / 7 \\
35 / 15 \\
\mathrm{~m} 9\end{array}$ & $\begin{array}{l}61 \\
61 \\
97 \cdot 5\end{array}$ & $\begin{array}{l}25 / 4 \\
25 / 12 \mathrm{~m} 14 \\
\text { a } 6 \text { v } 15 \\
\text { m } 9\end{array}$ & $\begin{array}{l}65 \\
67 \\
99\end{array}$ \\
\hline \multirow[t]{2}{*}{$\begin{array}{l}\text { Left ventricle } \\
\text { Aorta }\end{array}$} & $70 / 12$ & $97 \cdot 5$ & $\begin{array}{l}100 / 10 \\
100 / 50\end{array}$ & 99 \\
\hline & & & \multicolumn{2}{|c|}{$\begin{array}{l}\mathrm{Qp}=2.51 / \mathrm{min} \text { per } \mathrm{m}^{2} \\
\mathrm{Qs}=1.91 / \mathrm{min} \text { per } \mathrm{m}^{2} \\
\text { Pulmonary arteriolar } \\
\text { resistance }=2 \text { units }\end{array}$} \\
\hline
\end{tabular}

Qp, pulmonary blood flow; Qs, systemic blood flow.

She was referred to this clinic at 16 months of age when she was asymptomatic and acyanotic. The heart was clinically enlarged. There was a grade $2 / 6$ regurgitant systolic murmur at the apex and a $2 / 6$ continuous murmur at the third left interspace. The liver was palpable $2 \mathrm{~cm}$ below the right costal margin. The chest $x$-ray showed moderate cardiomegaly. The electrocardiogram disclosed left ventricular hypertrophy, $\mathrm{T}$ inversion in V5 and V6, and 
left anterior hemiblock. QRS was $0 \cdot 1 \mathrm{~s}$ in duration. She remained well on treatment with digoxin. The subsequent $x$-ray and electrocardiogram showed some improvement. The only symptom was dyspnoea on prolonged exertion.

She was recatheterised on 31 August 1976 (Table). Though oximetry showed no definite evidence of shunting dye dilution curves with injection into both left ventricle and aorta and sampling in the main pulmonary artery disclosed a left-to-right shunt. Anomalous origin of the left coronary artery draining into the pulmonary artery was diagnosed. The right coronary artery was dilated and tortuous. The left ventricle was dilated and contracted poorly. Grade 2 mitral regurgitation was present (Fig. 1). The day after the cardiac catheterisation she developed ventricular fibrillation but was resuscitated. In view of this event early operation was advised.

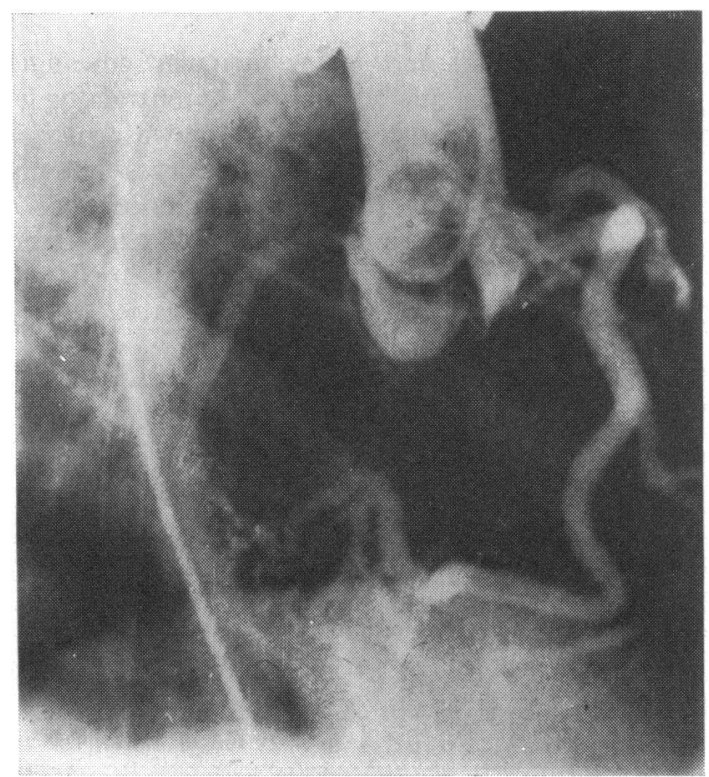

Fig. 1 The anomalous left coronary artery shunting into the main pulmonary artery.

\section{OPERATION}

The heart and great vessels were exposed through a median sternotomy. The great vessels were normal in size. A soft thrill was felt over the main pulmonary artery. The right coronary artery was large and tortuous. The left coronary artery was approximately $3.5 \mathrm{~mm}$ in diameter and divided early from a short main stem. It arose low down within the posterolateral pulmonary sinus. The thick-walled left ventricle contracted poorly.

The comparatively short length and small calibre
D. I. Hamilton, P. K. Gho:h, and R. F. Donnelly

of the left coronary artery before bifurcation con- $\overrightarrow{\vec{c}}$ traindicated the insertion of a vein graft between the aorta and the left main coronary artery. The deep등 position of the aberrant coronary ostium within the $\overline{\bar{c}}$. lateral pulmonary sinus suggested that its removal $\widehat{\nabla}$ from that site would have been both difficult and $\frac{\varrho}{\rho}$ dangerous, and for this reason the left subclavian ${ }^{\infty}$ artery was not divided and turned down for such $\vec{\circ}$ an anastomosis (see below).

Cardiopulmonary bypass was instituted with $\vec{\omega}^{\omega}$ cannulation of the venae cavae and the ascending aorta. Perfusion cooling to $18^{\circ} \mathrm{C}$ with circulatory arrest for 60 minutes after exsanguination was em-. ployed. The main pulmonary artery was opened $\vec{\sim}$ vertically. An aortopulmonary fistula $6 \mathrm{~mm}$ in diameter was created. A pericardial baffle was then 은 inserted to cover the fistulous opening and wassutured along the posterior wall of the pulmonary artery and over the ostium of the left coronary? artery. This ballooned up on releasing the aortici clamp and appeared to compromise the lumen of $\vec{\theta}$ the main pulmonary artery. A diamond-shaped $\stackrel{0}{0}$ 'dacron' gusset was, therefore, inserted into the anterior wall of the pulmonary artery down to theo level of the valve ring (Fig. 2).

\section{POSTOPERATIVE PROGRESS}

The postoperative recovery was uneventful. The $\triangle$ child remains well and is active 17 months after $\overrightarrow{0}$ operation. There is a faint thrill and a systolic 3 murmur over the pulmonary artery. The electrocardiogram continued to show left anterior hemiblock. Echocardiography revealed a left ventricular end-diastolic dimension of $3.0 \mathrm{~cm}$ and a left ven- $\frac{0}{7}$ tricular end-systolic dimension of $2.3 \mathrm{~cm}$ comparedo with left ventricular end-diastolic of $3.6 \mathrm{~cm}$ and left ventricular end-systolic of $3.2 \mathrm{~cm}$ preopera-尺̊ tively. This suggests a reduction of left ventricular $₹$ size and improved contractility. The systolic motion of the septum remains anterior because of left anterior hemiblock.

\section{Discussion}

The most satisfactory method of treatment of anomalous origin of the left coronary artery has not? yet been defined. A number of techniques have beero employed in infancy and childhood with varying degrees of success. These are (1) ligation of the anomalous left coronary artery at its pulmonary end (Sabiston et al., 1960); (2) pulmonary artery constriction (Kittle et al., 1955); (3) establishment? of a two-coronary artery system by direct anasto- $\triangle$ mosis or interposition of a 'dacron' tube, autogenous or allogenic saphenous vein graft (Neches et al. 1974; Chiariello et al., 1975; Venugopal and Subra-O글 

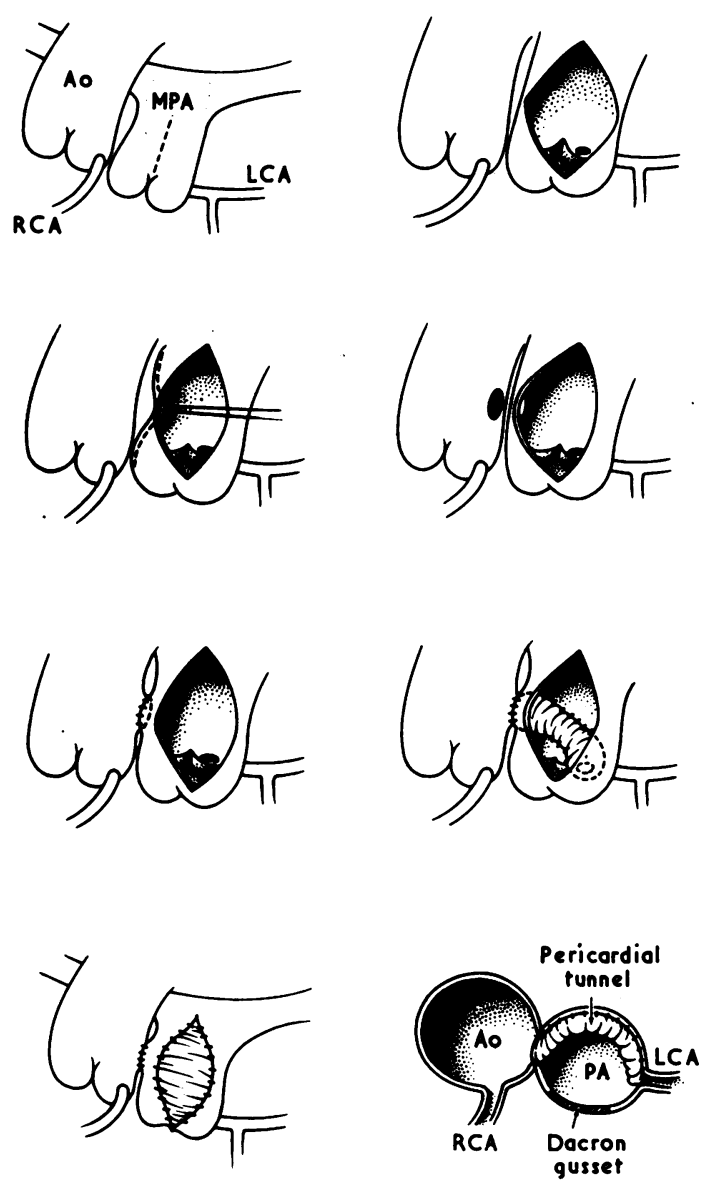

Fig. 2 The steps of the operation.

manian, 1975; Matsumoto et al., 1976); (4) left subclavian artery-left coronary artery anatomosis (Meyer et al., 1968; Pinsky et al., 1976). Turina and coworkers (1974) considered left coronary artery ligation and left ventricular aneurysmectomy as adequate therapy in a 4-month-old infant. Though left coronary artery ligation stops the left-to-right shunt, it leaves the heart with a single coronary artery system and does little to improve left ventricular function. The mortality rate is high in infancy and the survivors in the infant group might have lived without surgical treatment (Likar et al., 1966).

Stern and associates first reported the creation of an aortopulmonary fistula and insertion of an intrapulmonary baffle to connect the fistula to the ostium of the left coronary artery in 2 patients-a 4-month-old infant and a 21-year-old girl. The infant died in the postoperative period. However, in the older child the conduit remained patent, the heart size decreased, and the ventricular contractility improved (H. Sloan, 1977, personal communication).

The creation of an aortopulmonary fistula for the treatment of anomalous left coronary artery was first suggested by Gasul and Loeffler in 1949, with the aim of increasing the blood flow to the left coronary artery from the pulmonary artery. Potts (1955) created an aortopulmonary fistula in 2 patients to increase the pulmonary artery pressure as well as the oxygen content of the blood within the left coronary artery. Perhaps the direction of blood flow from the left coronary artery into the pulmonary artery was not appreciated at this time and the serious disadvantage of increasing the workload of an already damaged left ventricle was noticed to offset any possible benefit of increasing the pulmonary artery oxygen saturation.

In addition to the creation of an aortopulmonary fistula it is necessary to insert a baffle within the pulmonary artery to isolate the coronary artery blood flow effectively. In the unfavourable anatomical situation where the main left coronary artery is short, as seen in our patient, the excision of the left coronary artery ostium with a flange of pulmonary artery may be difficult and direct aortoleft coronary artery anastomosis or the interposition of a saphenous vein graft may not be possible. In our patient the left coronary artery ostium lay deep within the sinus of the pulmonary artery and any attempt to detach the left coronary artery ostium with a flange of surrounding tissue would have been technically dangerous. Bulging of the baffle inside the pulmonary artery could lead to obstruction of pulmonary blood flow. This was minimised in our patient by 'dacron' patch arterioplasty of the main pulmonary artery.

Though the clinical, haemodynamic, and echocardiographic studies confirm the satisfactory outcome of this procedure in the short term, long-term assessment will be required for the proper evaluation of this procedure as a reliable method for the correction of this congenital abnormality.

\section{References}

Augustsson, M. H., Gasul, B. M., Fell, E. H., Graettinger, J. S., Biscoff, J. P., and Waterman, D. F. (1962). Anomalous origin of left coronary artery from pulmonary artery. fournal of the American Medical Association, 180, 15-21. Billig, D. M. (1973). Congenital anomalies of the thoracic aorta and its branches. Progress in Cardiovascular Diseases, 16, 43-67.

Chiariello, L., Meyer, J., Reul, G. J., Hallman, G. L., and Cooley, D. A. (1975). Surgical treatment for anomalous origin of left coronary artery from pulmonary artery. Annals of Thoracic Surgery, 19, 443-450. 
Gasul, B. M., and Loeffler, E. (1949). Anomalous origin of left coronary artery (Bland-White-Garland syndrome) ? Reports of 4 cases. Pediatrics, 4, 498-507.

Likar, J., Criley, J. M., and Lewis, K. B. (1966). Anomalous left coronary artery arising from the pulmonary artery in an adult. Circulation, 33, 727-732.

Kittle, C. F., Diehl, A. M., and Heilbrunn, A. (1955). Anomalous left coronary artery arising from pulmonary artery. Fournal of Pediatrics, 47, 198-206.

Matsumoto, A., Sato, S., Kondo, J., Kumada, J., Goto, H., Kohno, M., Matsumura, H., and Niimura, I. (1976). Definitive surgical treatment of anomalous origin of left coronary artery - a new technical approach used successfully in a 7 month old male infant. Fournal of Thoracic and Cardiovascular Surgery, 72, 249-255.

Meyer, B. W., Stefanik, G., Stiles, Q. R., Lindesmith, G. G., and Jones, J. C. (1968). A method of definitive surgical treatment of anomalous origin of left coronary artery-a case report. Fournal of Thoracic and Cardiovascular Surgery, 56, 104-107.

Neches, W. H., Mathews, R. A., Park, S. C., Lenox, C. C., Zuberbuhler, J. R., Siewers, R. D., and Bahnson, H. T. (1974). Anomalous origin of left coronary artery from pulmonary artery: a new method of surgical repair. Circulation, 50, 582-587.
Pinsky, W. W., Fagan, L. R., Mudd, J. F. G., and Willman, V. L. (1976). Subclavian-coronary artery anastomosis in $\vec{S}$ infancy for the Bland-White-Garland syndrome. Fournal of Thoracic and Cardiovascular Surgery, 72, 15-20.

Potts, W. J. (1955). Quoted in Kittle et al. (1955).

Sabiston, D. C., Jr., Neill, C. A., and Taussig, H. B. (1960). The direction of blood flow in anomalous left coronary artery arising from the pulmonary artery. Circulation, 22, 591-597.

Thibert, M., Casasoprana, A., and Dupuis, C. (1973). Anomalous origin of left coronary artery from pulmonary artery. European fournal of Cardiology, 1, 500.

Turina, M., Real, F., Meier, W., and Senning, A. (1974). Left ventricular aneurysmectomy in a 4-month-old infant. fournal of Thoracic and Cardiovascular Surgery, 67, 915-919.

Van Praagh, R. (1973). Anatomy of coronary artery anomalies. European fournal of Cardiology, 1, 497.

Venugopal, P., and Subramanian, S. (1975). Anomalous origin of left coronary artery from pulmonary artery. Annals of Thoracic Surgery, 19, 451-456.

Requests for reprints to D. I. Hamilton, Esq., F.R.C.S., Royal Liverpool Children's Hospital, Myrtle Street, Liverpool. 